\title{
Health Belief Model-Based Education through Telegram Instant Messaging Services on Diabetic Self-Care
}

\section{ART I CLE IN F O}

\section{Article Type}

Original Research

\section{Authors}

Tavakoli R. ${ }^{1} P h D$,

Alipouran M. ${ }^{1} M S c$,

Zarei F* $P h D$

How to cite this article
Tavakoli R, Alipouran M, Zarei F.
Health Belief Model-Based Educ-
ation through Telegram Instant
Messaging Services on Diabetic
Self-Care. Health Education and
Health Promotion. 2018;6(3):91-
96.

*Health Education Department, Medical Sciences Faculty, Tarbiat Modares University.

Tehran, Iran

${ }^{1}$ Health Education \& Promotion Department, Medical Science Faculty, Research \& Science Branch, Islamic Azad University, Tehran, Iran

\section{Correspondence}

Address: Health Education Department, Medical Sciences Faculty, Tarbiat Modares University, Nasr Bridge, Jalal-Al-Ahmad Highway, Tehran, Iran

Phone: +98 (21) 82884546

Fax: +98 (21) 82884555

f.zarei@modares.ac.ir

\section{Article History}

Received: December 06, 2017

Accepted: February 25, 2018

ePublished: September 09, 2018

\section{A B S T R A C T}

Aims Today, Mobile Health interventions as a group of Electronic Health interventions used to provide health information and improve health outcomes. The aim of this study was to determine the effectiveness of the Health Belief Model-based (HBM) education on self-care in diabetic patient via Telegram, among participants.

Materials \& Methods This quasi-experimental study was done from Jun 2016 to September 2017 in the health centers of Tabriz. Out of 20 health complexes in Tabriz, randomized (stepwise sampling) 5 complex selected. Then from each complex, 2 health center was selected randomly. With randomly sampling method, 68 patients with diabetes were selected (34 participants in the intervention group and 34 participants in the control group). In intervention group, educational text messages based on HBM was sent via Telegram during one month regularly. Three months later, both Intervention and control group completed researchermade questionnaires by self-report. The data were analyzed by Chi-square test, paired t-test, Pearson's test and SPSS 19 software.

Findings There was no significant difference in several demographic characteristics between two groups. Comparison of the mean difference of knowledge and in HBM constructs before of intervention in the groups showed no significant difference $(p>0.05)$. There was a significant mean difference in the HBM constructs between two groups after intervention $(\mathrm{p}<0.05)$. There were significant correlations between the HBM constructs $(p<0.05)$.

Conclusion Educational messages improve the perception constructs of HBM constructs for adopting self-care behaviors.

Keywords Diabetes; Social Media; Education

\section{I T A T I O N L I N K S}

[1] Global estimates of the prevalence of diabetes for 2010 and 2030 [2] Diabetes Atlas [3] Iran diabetes research roadmap (IDRR) study: A preliminary study on diabetes research in the world and Iran [4] A review of eHealth interventions for physical activity and dietary behavior change [5] Diabetes app-related text messages from health care professionals in conjunction with a new wireless glucose meter with a color range indicator improves glycemic control in patients with type 1 and type 2 diabetes: Randomized controlled trial [6] Self care behavior among patients with diabetes in Harari, Eastern Ethiopia: The health belief model perspective [7] The effects of education based on extended health belief model in type 2 diabetic patients: A randomized controlled trial [8] Cost-effectiveness of a short message service intervention to prevent type 2 diabetes from impaired glucose tolerance [9] Mobile phone-based video messages for diabetes self-care support [10] The effect of instructional designed SMS based on Health Belief Model (HBM) on adoption of self-care behavior of patients with type II diabetes [11] Effect of distance education via short message service of mobile phones on self-efficacy and HbA1C of patients with type 2 diabetes mellitus [12] The effect of health belief model-based education through telegram instant messaging services on Pap smear performance [13] Evaluation of the effects of education based on health belief model on medication adherence in diabetic patients [14] The role of health beliefs in preventive behaviors of individuals at high-risk of type 2 diabetes mellitus [15] Effects of education based on health belief model on dietary adherence in diabetic patients [16] The effect of educational program based on health belief model on diabetic foot care [17] Effect of education program based on empowerment model in promoting self-care among type 2 diabetic patients in Isfahan 


\section{Introduction}

Diabetes is a worldwide epidemic of the 21st century, which is increasing rapidly. The International Diabetes Federation (IDF) estimates that 415 million adults have type 2 diabetes in 2015 in worldwide. The incidence of diabetes has already escalated to pandemic proportions, and the figure is expected to increase to 642 million in 2040. The growth of patient with diabetes in Iran, is predicted to be even greater than the global trend. Today, there are an estimated 4.6 million people with diabetes in Iran, which is $8.5 \%$ of the population $[1,2]$. According to the latest estimates, 35.4 million people, or $9.1 \%$ of the adult population, have diabetes in the Middle East and North Africa Region (MENA) where the Islamic Republic of Iran is belonged to, and this number is expected to almost double by 2035. Astonishingly, Iran owns the third place in terms of the total number of adult population with diabetes across the MENA region $(4,602.2$ adults with diabetes [20-79years] in $1000 \mathrm{~s}$ ) [3].

Type 2 diabetes is a complex metabolic disorder that is characterized by hyperglycemia. It is a chronic disease, and a multitude of daily self-care and complex care activities is required for the patient with diabetes. Therefore, there is a need to improve the awareness and behavior of self-care in diabetes among the public, including women. Today, Mobile Health (M-Health) interventions as a group of Electronic Health (E-Health) interventions used to provide health information and improve health outcomes. According to Norman et al.'s study, E-Health interventions are divided to the three generation that include: The first generation is the interventions in which applicants use a printed material such as brochures, reports and newssheets; the next generation is the interventions in which the training is media-based such as internet-Email, CD ROM, and Notebooks; and the third generation is the interventions in which the mobile phone is used as a Pocket PC. Some popular messaging, social media, and mobile based-applications such as Telegram, Viber, and what's App and Telegram-based interventions are included in the third generation ${ }^{4]}$. Many studies have revealed that using the text messaging applications and methods has a notable effect on diabetes control-care process of education to self-care management. The introduction of smartphones provides a factual chance to improve care in diabetes by empowering patients and Healthcare Professionals (HCPs) to give-and-take information remotely (Via SMS or email) to minimize or even eliminate the need for routine management office visits. Systematic reviews have indicated that health interventions improve diabetes care and facilitate patient involvement in the process of selfcare and improvement via text messaging (Short Message Service [SMS]). A meta-analysis showed that mobile phone interventions reduced $\mathrm{HbA} 1 \mathrm{c}$ by
$0.5 \%$ over 6 months, with more decreases in HbA1c in people with Type 2 diabetes mellitus (T2DM; $0.8 \%)$ than in those with T1DM $(0.3 \%)$. Moreover, in Saudi a study assessing the effect of SMS on glycemic control patients with T2DM revealed 5 to 7 texts per week were related to reductions in HbA1c after 4 months. The effectiveness of daily SMS measured by a study compared with weekly (Then once every two weeks) telephone follow-ups conveyed similar improvements in HbA1c in each group, that SMS can be considered an appreciated channel to ease diabetes care-control [5].

In several studies, the effectiveness of verbal training in terms of the Health Belief Model (HBM) of doing the self-care behavior is reviewed and approved [6, 7]. In addition, in some studies, the education via SMS by mobile phone has been effective on diabetes management [8, 9]. However, few studies have been found on the effect of modern education as the interventions based on instant messaging tools (The third generation of interventions) on improving the preventive behaviors, such as self-care in diabetes. They are, sometimes, contradictory.

The aim of this study was to determine the effectiveness of the HBM-based education on selfcare in patient with diabetes via Telegram, among participants.

\section{Materials and Methods}

This quasi-experimental study was done from Jun 2016 to September 2017 in the health centers of Tabriz. Out of 20 health complexes in Tabriz, randomized (Stepwise sampling) 5 complex selected. Then from each complex, 2 health center was selected randomly. Each complex health center included 5 health center. Using random sampling, 7 patients were invited to the study for each center. The inclusion criteria included being able to read and write, having an active health profile in Tabriz health care centers, having a smart cell phone, being familiar with Telegram performance as a social media, being aged at 30-60 years with at least one year history of suffering from Type 2 diabetes, and having no diagnosed acute side-effects due to their disease. The exclusion criteria included inability to continue participation for at least 3 months and suffering from diagnosed acute type 2 diabetes.

The Sample size was calculated according to a study conducted by Baghiani-Moghadam et al., the first study that used Text-Message Theorized-intervention in diabetes and estimated 31 participants in each group, using G-Power 3 [10]. For probable sample attrition, it was estimated for 35 people.

Then the second author (MAL), who is experienced as a health worker for 12 years, checked the eligibility of participants by reviewing their health profile. She called them for participating in the study by phone call and clarified them about the aim of the study. In 
addition, according to the number of people covered by each center, the participants were divided into two separate control and intervention groups (34 person in each group). Notably, one of control and one of the intervention group were excluded in order to lack ongoing collaboration. Ultimately, 34 patients with type 2 diabetes in each group took part in the study and their data were analyzed.

Method and data collection: In the intervention group, after completing the written informed consent, the individual's phone numbers were taken to communicate educationally through Telegram and their membership in Telegram, was assured. Then they were asked to complete the questionnaires at first. The participants in the intervention group received text messaging, infographic, podcasts, and video tutorials in diabetes related issue. The participants received at least 3 Types of messages at 10 AM per day from Saturday to Thursday during four weeks. Sending the educational content based on HBM as a theoretical framework of this study was done in the form of a regular schedule as follows:

Week 1: Informing about type 2 diabetes, and the process of diabetes happens (Increasing the knowledge in cognitive domain).

Week 2: Making susceptibility against the risk of diabetes, perceiving severity and seriousness of the disease (Increasing perceived threatened in perception domain).

Week 3: Informing about the benefits of self-care and changing life style as recommended approach (Increasing perceived benefits and health motivation in perception domain).

Week 4: Observing some tips for self-care in patients with diabetes and perceived barriers (Management of perceived barriers in psychomotor domain).

At the end of each day the participants were asked for their feedback by the sentence of "Yes, I saw and read the message". Moreover, they were assessed at the end of each week for answering several questions about the received messages during the week. In another meaning in the present study, there were two types of feedbacks; once for receiving the messages from participants, then to the understanding of them.

There was an interactive communication between the participants and the health educator (MAL). In order to provide cues to action until one month after the training, every week, and two text messages were sent along with the posters for the intervention group. The participants in the control group accomplished the questionnaires, right after completing the written informed consent form, but did not receive any training until the end of the study. Immediately after the end of the training (One month after the start of the study), the participants in both groups gathered in their own region health center and completed the second stages of the questionnaires. Then, three months after the training, the participants in both groups completed the questionnaires, and their data were analyzed.

Instruments and measures: Data collection tool in the study was a valid researcher-made questionnaire. Overall internal reliability or Cronbach's alpha was equal to 0.720 [10].

The tool consisted of three parts:

The first section contains demographic characteristics with 4 items including age, marital status, the participants' educational level, and history of other diseases.

The second section contains 11 multiple-choice items related to measuring the knowledge about type 2 diabetes. For each true answer, a positive point, and for each false answer, no point was appointed.

The third section was related to the problem based on constructs of HBM and included 27 items about individual beliefs about self-care in diabetes, which include perceived susceptibility (4 items), perceived severity (4 items), perceived benefits ( 4 items), perceived barriers ( 4 items), and self-efficacy (11 items); The more Wight of questions in construct of self-efficacy may emphasis proving self-efficacy in self-care ability for patients with diabetic need breaking up main skills in sequential stages. All with a five-point-Likert scale with the score of 1 (Strongly disagree) to 5 (Strongly agree) were ranked as higher scores indicating agreement with the beliefs of health assessment.

The data were analyzed Chi-square test, paired t-test, Pearson's test and with SPSS 19 software.

\section{Findings}

The mean age of the subjects in the intervention and control group was $45.59 \pm 8.00$ and $50.88 \pm 6.97$ years, respectively. About $67.6 \%$ of the participants were female, the rest of them were male.

There was no significant difference in several demographic characteristics like gender, marital status and job between two groups ( $p>0.05$; Table 1).

Table 1) Statistical frequency of demographic characteristics in two study groups (The numbers in parentheses represent percentage, $n=34$ in each group)

\begin{tabular}{lccc}
\multicolumn{1}{c}{$\begin{array}{c}\text { Demographic } \\
\text { variables }\end{array}$} & $\begin{array}{c}\text { Intervention } \\
\text { group }\end{array}$ & $\begin{array}{c}\text { Control } \\
\text { group }\end{array}$ & P-value \\
\hline $\begin{array}{l}\text { Gender } \\
\text { Male }\end{array}$ & $11(32.4)$ & $11(32.4)$ & \\
female & $23(67.6)$ & $23(67.6)$ & 1.000 \\
Marital status & & & \\
$\begin{array}{l}\text { Married } \\
\text { Single }\end{array}$ & $\begin{array}{c}33(97.1) \\
\text { Job }\end{array}$ & $\begin{array}{c}31(91.2) \\
3(8.8)\end{array}$ & 0.303 \\
Housewife & $19(55.9)$ & $21(61.8)$ & 0.622 \\
Other & $15(44.1)$ & $13(38.2)$ & \\
Educational level & & & \\
Under diploma & $14(41.2)$ & $23(67.6)$ & 0.28 \\
Diploma and more & $20(58.8)$ & $11(32.4)$ & \\
Age (years) & & & \\
30-39 & $9(26.5)$ & $1(2.9)$ & \\
$40-49$ & $12(35.3)$ & $11(32.4)$ & 0.13 \\
$50-60$ & $13(38.2)$ & $22(64.7)$ & \\
\hline
\end{tabular}

Summer 2018, Volume 6, Issue 3 
Comparison of the mean difference of knowledge and in HBM constructs before intervention in the groups showed no significant difference ( $p>0.05)$, but there was a significant difference in the HBM constructs between the groups after intervention ( $\mathrm{p}<0.05$; Table 2).

There were significant correlations between the HBM constructs (Table 3).

Table 2) Comparison of mean difference of HBM constructs' scores before and after training in two groups ( $\mathrm{n}=34$ in each group)

\begin{tabular}{lccc}
\hline Constructs & Intervention group & Control group & P-value \\
\hline Knowledge & & & 0.967 \\
Before & $9.88+1.07$ & $9.67 \pm 1.18$ & 0.07 \\
After & $10.56+0.79$ & $10.07 \pm 2.46$ & - \\
p-value & 0.001 & 0.346 & 0.761 \\
Perceived susceptibility & & & 0.001 \\
Before & $13.53 \pm 1.66$ & $13.67+2.01$ & - \\
After & $14.88 \pm 1.30$ & $13.48+2.06$ & 0.627 \\
p-value & 0.001 & 0.32 & 0.003 \\
Perceived severity & & & - \\
Before & $10.73 \pm 2.25$ & $11.03 \pm 2.76$ & 0.917 \\
After & $12.79 \pm 1.87$ & $13.67 \pm 2.37$ & 0.008 \\
p-value & 0.001 & 0.921 & - \\
Perceived benefits & & & \\
Before & $13.61+2.28$ & $13.55 \pm 2.44$ & 0.106 \\
After & $14.91+1.38$ & $13.67 \pm 2.37$ & 0.0001 \\
p-value & 0.001 & 0.572 & - \\
Perceived barriers & & & \\
before & $7.76+2.54$ & $8.90 \pm 2.99$ & 0.337 \\
after & $4.36+1.00$ & $8.53 \pm 2.96$ & 0.086 \\
p-value & 0.001 & & -011 \\
Self-efficacy & & $15.93+2.91$ & - \\
Before & $15.15 \pm 3.45$ & $15.87+3.09$ & 0.791 \\
after & $17.27 \pm 2.28$ & & \\
p-value & 0.001 & & \\
\hline
\end{tabular}

Table 3) Correlation coefficient between the HBM constructs

\begin{tabular}{|c|c|c|c|c|c|c|c|c|c|c|c|c|}
\hline \multirow[t]{2}{*}{ Construct } & \multicolumn{2}{|c|}{ Knowledge } & \multicolumn{2}{|c|}{$\begin{array}{c}\text { Perceived } \\
\text { Benefits }\end{array}$} & \multicolumn{2}{|c|}{$\begin{array}{l}\text { Perceived } \\
\text { Severity }\end{array}$} & \multicolumn{2}{|c|}{$\begin{array}{c}\text { Perceived } \\
\text { Susceptibility }\end{array}$} & \multicolumn{2}{|c|}{$\begin{array}{c}\text { Perceived } \\
\text { Barriers }\end{array}$} & \multicolumn{2}{|c|}{ Self-Efficacy } \\
\hline & Before & After & Before & After & Before & After & Before & After & Before & After & Before & After \\
\hline \multicolumn{13}{|l|}{$\overline{\text { Knowledge }}$} \\
\hline Before & 1 & $0.426^{* *}$ & 0.211 & 0.84 & 110 & 0.176 & $.360^{* *}$ & $0.417^{* *}$ & $-0.393^{* *}$ & $-0.330^{* *}$ & 0.091 & 0.087 \\
\hline After & $0.426^{* *}$ & 1 & 0.162 & $0.242^{*}$ & 017 & & $46^{*}$ & $0.325^{* *}$ & $-0.450^{* *}$ & & 0.144 & $0.337^{* *}$ \\
\hline \multicolumn{13}{|c|}{ Perceived benefits } \\
\hline Before & 0.211 & 0.162 & 1 & $0.709^{* *}$ & $0.372^{* *}$ & $0.268^{*}$ & $0.534^{* *}$ & $0.381^{* *}$ & -0.076 & 0.019 & $0.433^{* *}$ & $0.333^{* *}$ \\
\hline After & 0.084 & $0.242^{*}$ & $0.709^{* *}$ & 1 & 0.190 & $0.499^{* *}$ & $0.397^{* *}$ & $0.542^{* *}$ & -0.024 & $-0.309 *$ & 0.209 & $0.530^{* *}$ \\
\hline \multicolumn{13}{|c|}{ Perceived severity } \\
\hline Before & 0.110 & 017 & $372 * *$ & 0.190 & 1 & $551^{* *}$ & .177 & 0.045 & 0.126 & 0.161 & 0.167 & 0.043 \\
\hline After & 0.176 & $025 A^{*}$ & $0.268^{*}$ & $0.499 * *$ & $0.551^{* *}$ & 1 & 200 & $0.340^{* *}$ & 0.004 & $-0.304 *$ & 0.138 & 0.394 \\
\hline \multicolumn{13}{|c|}{ Perceived susceptibility } \\
\hline Before & $0360^{* *}$ & $46^{*}$ & $534^{* *}$ & $0.397^{* *}$ & 0.177 & 0.200 & 1 & $0.770^{* *}$ & -0.180 & -0.073 & $0.254^{*}$ & $0.261^{*}$ \\
\hline After & $17 * *$ & & $381^{* *}$ & $0.542^{* *}$ & 0.045 & $340 * *$ & $770^{* *}$ & 1 & $-0.383^{* *}$ & -0.4 & 0.163 & $0.439 * *$ \\
\hline \multicolumn{13}{|c|}{ Perceived barriers } \\
\hline Before & $-0.393^{* *}$ & $-0.450^{* *}$ & -0.076 & -0.024 & 0.126 & 0.004 & -0.180 & $-0.383^{* *}$ & 1 & $0.659^{* *}$ & -0.256 & $-0.273^{*}$ \\
\hline After & $-0.330^{* *}$ & & 0.019 & $-0.309^{*}$ & 0.161 & $-0.304^{*}$ & -0.073 & $-0.421^{* *}$ & $0.659 * *$ & 1 & -0.010 & $-0.402^{* *}$ \\
\hline \multicolumn{13}{|l|}{ Self-efficacy } \\
\hline Before & 0.09 & 0 . & $0.433^{* *}$ & 0.299 & 0.167 & 0.138 & $0.254^{*}$ & 0.163 & -0.256 & -0.010 & 1 & $0.728^{* *}$ \\
\hline After & 0.087 & $0.337^{* *}$ & $0.333^{* *}$ & $0.530^{* *}$ & 0.043 & $0.394^{* *}$ & $0.261^{*}$ & $0.439 * *$ & $-0.273^{*}$ & $-0.402^{* *}$ & $0.728^{* *}$ & 1 \\
\hline
\end{tabular}

\section{Discussion}

The aim of this study was to determine the effectiveness of the HBM-based education on self-care in patient with diabetes via Telegram as the most popular social media among participants, Tabriz, Iran.

The findings of this study revealed that a theoretical educational intervention program via social media such as Telegram had more positive effect on the participants' awareness, and attitude in the intervention group. This was in line with the finding of other similar studies even in different issues [11,12]. The results of the present study indicated that the mean scores of perceived susceptibility were dramatically changed after a theoretical textmessaging intervention. This finding confirmed by 
several studies revealed the similar results [11, 13]. Furthermore, in another study, the application of educational text messages based on HBM in patient with diabetes confirmed that perceived susceptibility, perceived severity, perceived benefits, and perceived barriers, are aligned with the results of the present study [10]. It seems that patients found themselves defenseless to diabetes consequences and the educational program eventually flourished the vulnerability of diabetes as the multi-effect dilemma. The positive effect of educational messages designed in the present study in increasing the perceived susceptibility of patient with diabetes, is another important point to be noted as one influential individual approaches in self-care behaviors.

The increase in the mean score of perceived sensitivity in the intervention group confirms the effectiveness of educational messages in this field. This finding is similar to other studies in Iran $[14,15]$.

Given the positive impact of educational messages of increasing the average perceived severity of patient with diabetes in the intervention group, they understood that their illness can be a serious problem for their future. Therefore, it will cause people to avoid the behaviors that can increase complications of the disease, and in this way, they need to reduce these probable difficulties.

In the present study, the educational messages designed were able to increase the mean score of the perceived benefits of self-care behaviors in patients in the intervention group. Increased perceived benefits in other studies $[13,16]$, in diabetes have been reported.

Based on the results of the present study, the mean score of self-efficacy in the intervention group was increased. Other similar studies were lined with this finding [13]. In contrast to the results of this study, Baghiani Moghadam et al.'s study on the effect of educational SMS based on HBM on adoption self-care behaviors in patient with diabetes, there was no change in the self-efficacy of patient with diabetes [10].

Furthermore, the mean of self-care behaviors after intervention in the intervention and control group showed a significant difference in some of the questions. Increase of self-care behaviors has been confirmed in previous studies [10,17], there was no statistically significant difference between the intervention and control groups regarding all the questions of self-care behaviors. It can justify that behavior change takes more time, and in addition, other social and cultural factors also play a role in the behavior changing process.

The effectiveness of educational messages in improving the perception of HBM constructs for adopting self-care behaviors confirmed. No meaning full difference from a statistical perspective in knowledge revealed that social media naturally was a knowledge transfer and users of social media will

Health Education and Health Promotion bombard with varied messages. In contrast with the current hypothesis that education most probably affect awareness and knowledge after intervention and have dramatically difference between control and intervention groups, in this study, there was no significant difference between both intervention and control groups.

Given the fact that in chronic diseases such as patient with diabetes needs to be trained and continuously monitored throughout their life. The training method can be used to increase the level of consciousness and self-efficacy of the patients to be effective in their self-care.

However, the present study similar to the other interventional design experienced had several limitations that as following: There was a lack of interest for the participant to take part in this study since most of them had an active health profile in private clinics. Therefore, calling for participating in the study for the phase of the pretest did not go up on time. Moreover, for the old generation, there was no interest also for receiving the text educational message, particularly by social media. Thus the motivation phase to persuade them for collaboration was time-consuming too.

Using modern educational technology, including social media and mobile -application for some public health issues such as self-care in diabetes would be more cost benefit than lecture-based education. Developing international education in self-care for patient with diabetes using Mobile-Application are strongly suggested for future health educational program.

\section{Conclusion}

Educational messages improve the perception constructs of HBM constructs for adopting self-care behaviors.

Acknowledgements: Authors gratefully acknowledge all persons who helped us in this study.

Ethical permissions: The required permissions were obtained from the Vice-Chancellor for Science and Research Branch, Islamic Azad University. Also the study was approved by the University Ethics Committee (Ethic No: IR.IAU.SRB.REC.1396.18). Then the second author MAL introduced to Tabriz University of Medical Education and Health Services. The aim of the study was orally clarified to the potential participants who met the inclusion criteria. The participants were told that they are permitted to withdraw from the study at any time they want while all information would be kept in secret.

Conflicts of Interests: The Authors state that there is no conflict of interests.

Authors' Contribution: Tavakoli R. (First author), Original researcher (20\%); Alipouran M. (Second author), Statistical analyst (20\%); Zarei F. (Third author),

Introduction 
uthor/Methodologist/Assistant researcher /Discussion author (60\%)

Funding/Support: This study was supported financially by Research \& Science Branch, Islamic Azad University, Tehran, Iran.

\section{References}

1- Shaw JE, Sicree RA, Zimmet PZ. Global estimates of the prevalence of diabetes for 2010 and 2030. Diabetes Res Clin Pract. 2010;87(1):4-14.

2- Mbanya JC, Delice Gan D, Allgot B, Bakker K, Betz Brown J, et al. Diabetes Atlas [Internet]. Brussels: International Diabetes Federation; 2006 [cited 2016 May 14]. Available from: file:///C:/Users/Geshani/Downloads/DiabetesAtlas-3rd-edition.pdf.

3- Nasli Esfahani E, Farzadfar F, Kouhnavard M, Ghodssi Ghassemabadi R, Khajavi A, Peimani M, et al. Iran diabetes research roadmap (IDRR) study: A preliminary study on diabetes research in the world and Iran. J Diabetes Metab Disord. 2017;16:9.

4- Norman GJ, Zabinski MF, Adams MA, Rosenberg DE, Yaroch AL, Atienza AA. A review of eHealth interventions for physical activity and dietary behavior change. Am J Prev Med. 2007;33(4):336-45.

5- Grady M, Katz LB, Cameron H, Levy BL. Diabetes apprelated text messages from health care professionals in conjunction with a new wireless glucose meter with a color range indicator improves glycemic control in patients with type 1 and type 2 diabetes: Randomized controlled trial. JMIR Diabetes. 2017;2(2):e19.

6- Ayele K, Tesfa B, Abebe L, Tilahun T, Girma E. Self care behavior among patients with diabetes in Harari, Eastern Ethiopia: The health belief model perspective. PloS One. 2012;7(4):e35515.

7- Bayat F, Shojaeezadeh D, Baikpour M, Heshmat R, Baikpour M, Hosseini M. The effects of education based on extended health belief model in type 2 diabetic patients: A randomized controlled trial. J Diabetes Metab Disord. 2013;12:45.

8- Wong CKH, Jiao FF, Siu SC, Fung CSC, Fong DYT, Wong
KW, et al. Cost-effectiveness of a short message service intervention to prevent type 2 diabetes from impaired glucose tolerance. J Diabetes Res. 2016;2016:1219581. 9- Bell AM, Fonda SJ, Walker MS, Schmidt V, Vigersky RA. Mobile phone-based video messages for diabetes self-care support. J Diabetes Sci Technol. 2012;6(2):310-9.

10- Baghiani Moghadam MH, Taheri G, Fallah Zadeh H, Parsa M. The effect of instructional designed SMS based on Health Belief Model (HBM) on adoption of self-care behavior of patients with type II diabetes. Mod Care J. 2014;11(1):10-8. [Persian]

11- Goodarzi M, Sarmadi MR, Saeed N. Effect of distance education via short message service of mobile phones on self-efficacy and $\mathrm{HbA1C}$ of patients with type 2 diabetes mellitus. 2015;4(2):1-13. [Persian]

12- Khademolhosseini F, Noroozi A, Tahmasebi R. The effect of health belief model-based education through telegram instant messaging services on Pap smear performance. Asian Pac J Cancer Prev. 2017;18(8):2221-6. 13- Farahani Dastjani F, Shamsi M, Khorsandi M, Ranjbaran M, Rezvanfar M. Evaluation of the effects of education based on health belief model on medication adherence in diabetic patients. Iran J Endocrinol Metab. 2016;18(2):83-9. [Persian]

14- Mazloomy S, Mirzaei A, Afkhami Ardakani M, Baghiani Moghadam M, Fallahzadeh $\mathrm{H}$. The role of health beliefs in preventive behaviors of individuals at high-risk of type 2 diabetes mellitus. J Shahid Sadoughi Univ Med Sci. 2010;18(1):24-31. [Persian]

15- Mardani Hamuleh M, Shahraki Vahed A, Piri AR. Effects of education based on health belief model on dietary adherence in diabetic patients. Iran J Diabetes Lipid Disord. 2010;9:1-6.

16- Hazavehei SMM, Sharifirad G, Mohabi S. The effect of educational program based on health belief model on diabetic foot care. Int J Diabetes Dev Ctries. 2007;27(1):18-23.

17- Shojaeezadeh D, Tol A, Sharifirad G, Alhani F. Effect of education program based on empowerment model in promoting self-care among type 2 diabetic patients in Isfahan. Razi J Med Sci. 2013;20(107):18-31. [Persian] 